\title{
Improved Modelling of Soil Loss in El Badalah Basin: Comparing the Performance of the Universal Soil Loss Equation, Revised Universal Soil Loss Equation and Modified Universal Soil Loss Equation Models by Using the Magnetic and Gravimetric Prospection Outcomes
}

\author{
Naima Azaiez ${ }^{1,2,3}$ (1) \\ ${ }^{1}$ King Khalid University, Faculty of Human Sciences, Abha, Saudi Arabia \\ ${ }^{2}$ Preparatory Institute for Literary Studies and Human Sciences of Tunis I (IPELSHT), Tunis, Tunisia \\ ${ }^{3}$ Research Laboratory: "Biogeography, Applied Climatology and Environmental Dynamics” (BICADE), Faculty of Arts and \\ Humanities of Manouba, Tunis, Tunisia \\ Email: nazaiez@kku.edu.sa, azaieznaima@yahoo.fr
}

How to cite this paper: Azaiez, N. (2021). Improved Modelling of Soil Loss in El Badalah Basin: Comparing the Performance of the Universal Soil Loss Equation, Revised Universal Soil Loss Equation and Modified Universal Soil Loss Equation Models by Using the Magnetic and Gravimetric Prospection Outcomes. Journal of Geoscience and Environment Protection, 9, 50-73.

https://doi.org/10.4236/gep.2021.94005

Received: February 26, 2021

Accepted: April 17, 2021

Published: April 20, 2021

Copyright $\odot 2021$ by author(s) and Scientific Research Publishing Inc. This work is licensed under the Creative Commons Attribution International License (CC BY 4.0).

http://creativecommons.org/licenses/by/4.0/

(c) (i) Open Access

\begin{abstract}
Water erosion is a natural fact in the cycle of shaping the earth's landforms and the most evident form of land degradation on a planetary scale (Roose \& De Noni, 2004; Dautrebande \& Sohier, 2006; Toumi et al., 2013; Azaiez, 2020a). Its effects have largely affected the rural landscape. Although it is the result of an ancient and primeval climatic and tectonic forcing, man's footprint in its intensification remains a reality. A real awareness of this problem on the part of scientists is reflected in the many studies on understanding the risks. Experiments have been carried out, equations and models have been developed with the aim of preserving the soil. The watershed of wadi El Badalah, the subject of this study, is not excluded from this risk. The present research is a new comparative contribution to the quantification of soil loss based on four empirical models (Universal Soil Loss Equation USLE, Revised Universal Soil Loss Equation RUSLE, Modified Universal Soil Loss Equation MUSLE and the adjusted model). The main objective of this research project is to test several empirical models of quantification of soil loss, extensively tested on a global scale, to discuss the potential of each model in order to choose the most appropriate for the El Badalah basin. The method is based on geotechnical and geophysical investigations. It consists of determining the anomalies of the subsoil based on the difference in density and the resistivity
\end{abstract}


of the heterogeneous constituents of the subsoil. This is in order to look for sectors potentially favorable to infiltration at the expense of runoff.

\section{Keywords}

Adjustment Process, Magnetic and Gravimetric Prospection, Soil Loss, USLE, RUSLE and MUSLE Models

\section{Introduction}

Today, the problem of erosion is taking on a social dimension as the little viable agricultural land is at risk of degradation to varying degrees due to changes in land use and the adoption of farming methods that are not appropriate for certain types of soil, especially those located in areas at high risk of landslides (Roose and De Noni, 2004; Felah, 2010; Azaiez, 2016, 2020a; Azaiez et al., 2020). Because the steep slopes are unstable and when soil becomes saturated in water it may be well prepared to fall. The present research focuses on the phenomenon of soil degradation in the watershed of Wadi El Badalah, a northern tributary of Wadi Tiah coming from the highlands surrounding Akabet Chaar. This small watershed has known an agricultural development which is reflected in the presence of a system of well-maintained agricultural terraces at the bottom of a particularly rough relief, especially in the western area of this watershed. It is frequently subject to hydrological accidents which are at the origin of the degradation of the arable layer of the soil on the slopes of the El Kharja and El Karine mountains (Figure 1).

The interest in this topic comes from the need to preserve these agricultural terraces against erosion. Both rill erosion and gully erosion are constantly gaining ground at the expense of agricultural land, but at a very variable interannual rate. Good management of soil loss necessarily starts with a better understanding of the hydrological behavior of the watershed, which should not be based on an exclusively statistical model because erosion works through processes that are spatio-temporally variable. Therefore, it would not be advisable to assess them by their statistical weight, but rather by their causal relationship due to their various aspects and behaviors, especially with respect to exceptional rainfall events and the ancient volcanic substratum worn out by the weathering mechanisms (mechanical and chemical).

In this perspective, it was chosen to assess soil losses through a comparative test between the three models (USLE, RUSLE and MUSLE) in order to understand the different circumstances and processes that are at the origin of land degradation in the El Badalah watershed. Adapting these universal equations of soil loss to the local conditions of the watershed using the existing knowledge and finding related to magnetic and gravimetric prospection, may provide new insights into water erosion, an issue which has attracted the attention of several researchers. Adapting these universal soil loss equations to local watershed conditions 


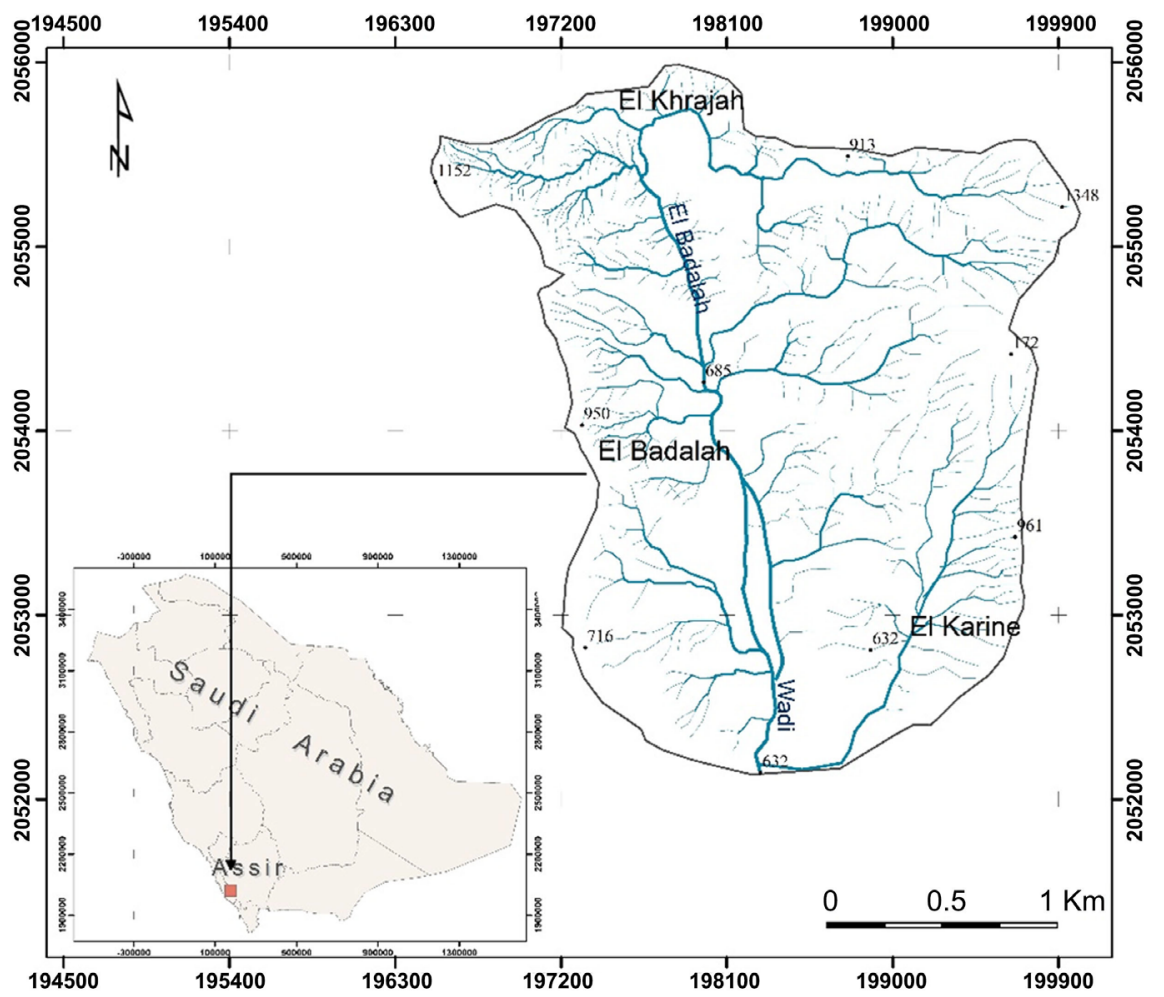

Figure 1. Location map of the El Badalah basin (Source: Google Earth pro 2020 Satellite Images exported on UTM projection through the map Puzzle software).

using existing knowledge and findings related to magnetic and gravity prospecting, can provide new insights into water erosion by seeking out the most favorable areas to infiltration and to identify potentially favorable sectors for the proliferation and deepening of the horizon of biological weathering as being a natural mechanism for the restitution of the soil layer recently opposed to erosion process.

\section{Study Area}

El Badalah basin in the southwest of Saudi Arabia, is marked by a controversial and dissected topography with an average slope around $45^{\circ}$. Steep slopes were mostly opposed to steep-walled valleys and deep fluvial dissection in the central section of El Badalah wadi $\left(60^{\circ}\right.$ to $\left.87.6^{\circ}\right)$. The slopes underlain by deeply weathered basaltic and metamorphic rocks. The topography slopes gently down from the east mountains and increased slightly in the west (Figure 2).

This watershed is formed by basaltic rocks, known as basement rocks and classified as continental rift basalts (Adelinet, 2010). The question that arises is how does soil erosion from basaltic rocks take place? And how do the slopes become destabilized despite the strength and rigidity of the underlying basaltic rocks? In fact, careful geological studies carried out on basaltic formations have shown that basaltic reliefs can show some signs of weakness due to several reasons, among others, climate change and human pressure. These ancient rocks of 


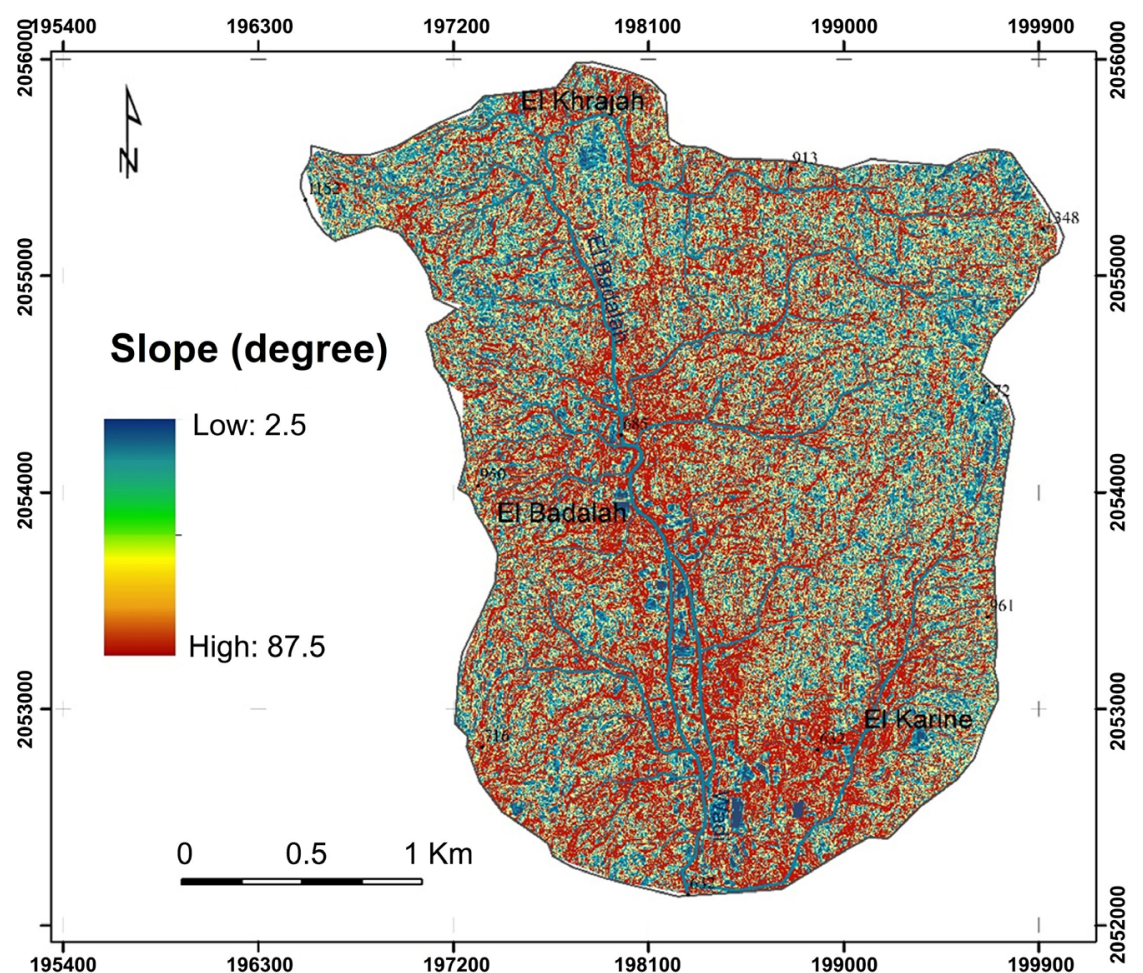

Figure 2. Slope map of the study area by using the SRTM digital elevation data, produced by NASA.

the Assir region are the result of a discontinuous functioning of the magmatic system (intrusive and eruptive). As a matter of fact, the lava layers that form the different basalt layers are not perfectly stacked. They are frequently separated by sectors called the interflow spaces, leading to a disturbance in stratification, thus discontinuities and inconsistencies occur in these basaltic rocks (Adelinet, 2010; Fontes et al., 2004; Shi, 2014; Solleiro-Rebolledo et al., 2019). The formation of the interflow spaces can be explained by several facts including the irregular slope during the cooling of the lava, the fluctuations of intrusions and volcanic eruptions on a geological scale, and finally the alterations brought by late tectonic accidents and the cumulative effects of weathering and erosion that marked the various climatic episodes, especially that of the Quaternary (Elawadi et al., 2012). All these facts were at the origin of the heterogeneity of these basaltic formations with frequent layers of sandstones and conglomerates. Given their very ancient volcanic origin, the upper slopes are formed by infertile soils that are very sensitive to the water stress of the long dry season due to their low content of clay minerals frequently leached by runoff water (Fontes, Pereirab, \& Smith, 2004; Adelinet, 2010; Solleiro-Rebolledo et al., 2019). The fertile soils are the alluvial soils on the middle and lower slopes and those along Wadi El Badalah. These rich and deep soils contain more newly formed clay elements (Kaolinite and smectite) that allow them to retain sufficient moisture for a long period of time, even with the advent of the dry period, which can retain an acceptable vegetation cover. It is these soil compartments that require priority preservation, 
given their farming potential on the one hand, and the influence of runoff on the other (Shi, 2014; Solleiro-Rebolledo et al., 2019). These soils are of capital importance as they are formed on a system of coalescent alluvial fans connected to more recent alluvial terraces. These alluvial terraces hold slightly coarse alluvial formations that are fairly porous and permeable with sufficient water potential for the sustainability of an agricultural activity based on cereals and seasonal vegetables (Photo 1) (Ben Menaa el Amri, 2007). Indeed, the state of the different types of alluvial terraces provides information on the spatiotemporal variation and the rhythm of the erosive manifestation in the different compartments of this watershed. Thus, a distinction is made between stepped terraces, located on the eastern tributaries of the Wadi el Badalah, and nested terraces located on the western slopes. These nested terraces are perfectly connected to the alluvial fans located upstream at the exit of the gorges.

\section{The stepped terraces of the eastern tributaries:}

Currently, they remain in the form of strips of small area and thickness with an erosion talus well marked in the landscape. This confirms that they are the result of a succession of short accumulation episodes and long and accentuated erosion episodes. Under these conditions, the flow managed to incise the pre-existing alluvial deposit and the underlying bedrock (Posthumus, 2005; Bridgland, Westaway, \& Cordier, 2009).

Nevertheless, the role of other factors should be emphasized, notably the context of the opening of the Red Sea and its effects on the layout of these Quaternary formations. In the context of torrential rains, they play a key role in water and sediment retention (Photo 2).

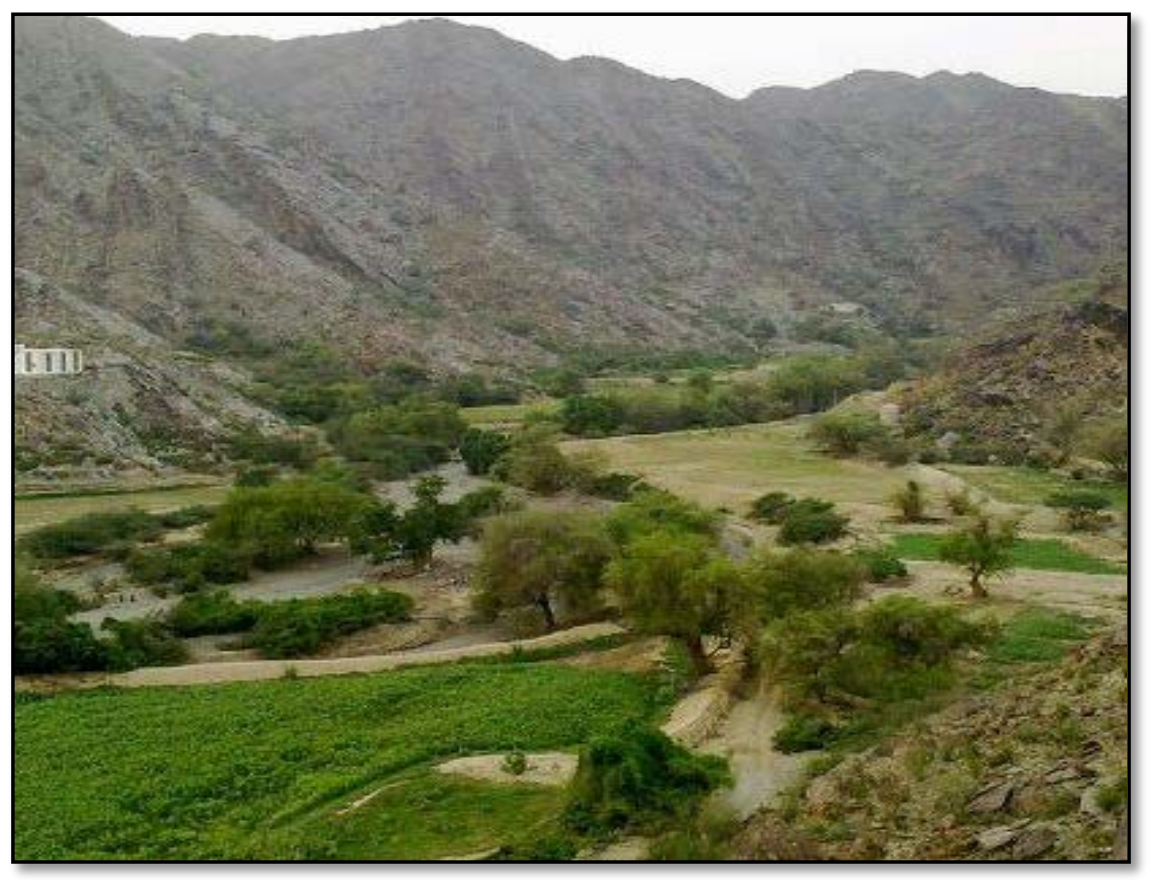

Photo 1 . The stability of agricultural terraces has made agriculture sustainable in the El Badalah basin (Source: Meflah El Harithi photo, 2017). 


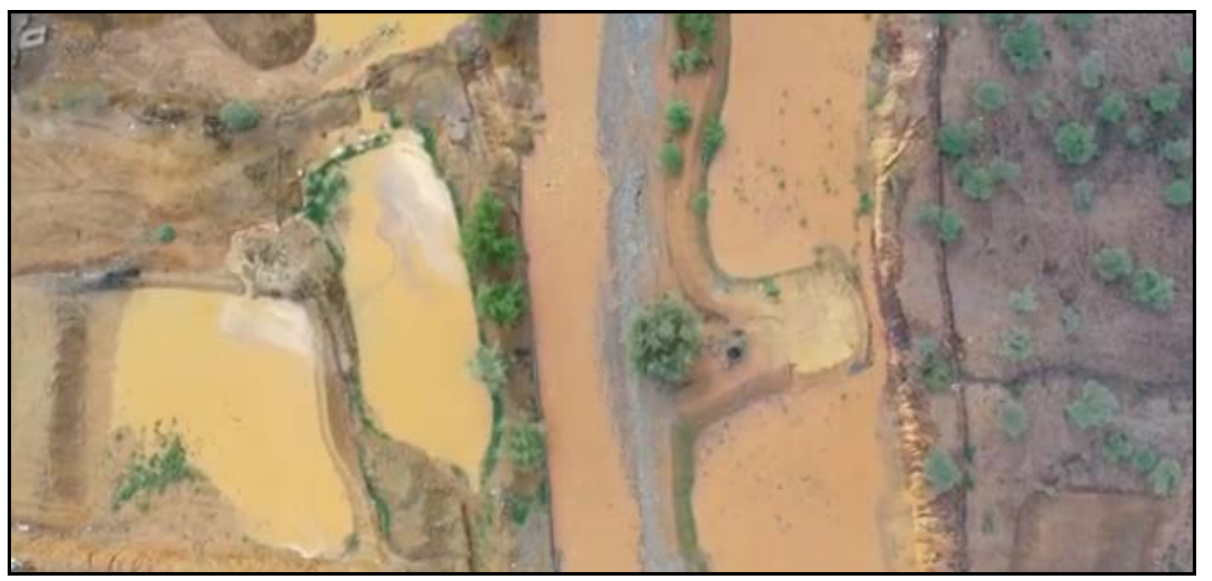

Photo 2. The water retention capacity of agricultural terraces in the El Badalah basin. (Source: Meflah El Harithi photo, 2017).

\section{Nested terraces in the western part of the watershed:}

At least two nested terraces exist, of which the upper one is directly connected upstream to alluvial fans. Alluvial terraces in this small watershed have been found to be atypical and cannot be attributed exclusively to climatic causes (Bridgland, Westaway, \& Cordier, 2009). By examining the different features of these terraces, it was found that the soils on nested terraces are better preserved than those on stepped ones. This finding is also proved by superimposing the soil loss map resulting from the modeling with that of the distribution of alluvial terraces.

The natural plant cover is formed of oleaster, tamarix and acacia on the middle and lower slopes, while juniper occupies the upper slopes. The vegetation is more dense on the western and northeastern slopes and less and less dense in the central and extreme southeastern part (Figure 3).

This vegetation cover, by its nature and density, constitutes a fundamental parameter in the study of erosion. It will be taken into consideration in the modeling of soil loss. On the pedological level, there is not sufficiently detailed pedological information available to assess the behavior of the different types of soils. The mapping of the pedological compartments is based on the topo-sequential method using the available pedological sketch, the results of soil analyses presented in scientific research and the background of the geological map to highlight the lateral variations of the pedological compartments. But also, by the application of the sand equivalent test on certain samples taken in this watershed. The land cover map is created using image supervised classification approaches for the year of 2020 .

\section{Methodology of Work}

The models used in the quantification of soil losses in the El Badalah watershed start from the basic Wischmeir equation (USLE) (Wischmeier \& Smith, 1975, 1978). All the other models derived from this one, are mostly based on 


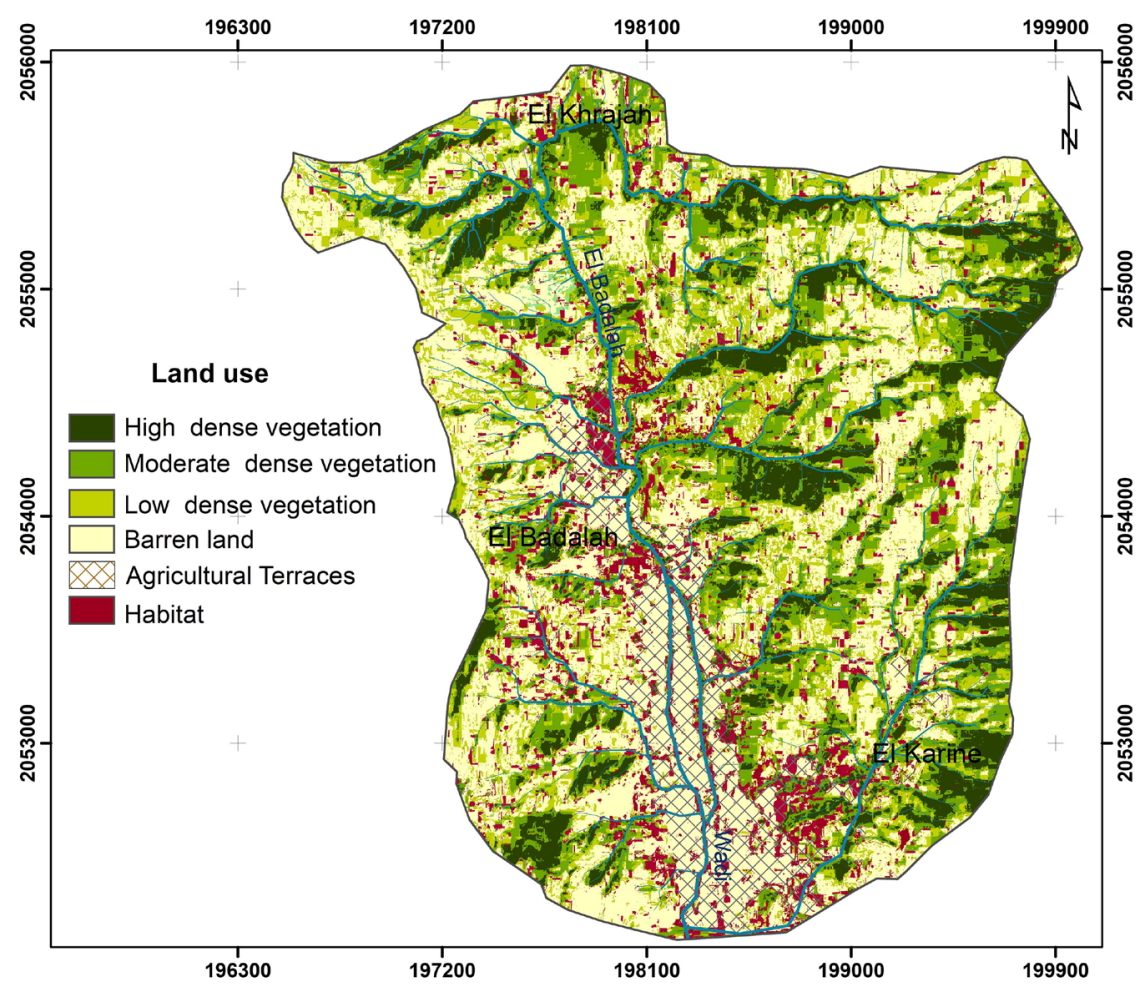

Figure 3. Land use map of El Badalah basin in 2020 (Source: Google Earth pro 2020 Satellite Images exported on UTM projection through the map Puzzle software).

additional inputs whose objective is to study all the factors that control land erosion and which have not been taken into account in the reference formula ( $\mathrm{Sa}$ deghi et al., 2014; Djoukbala et al., 2018; Ezzaouini et al., 2020).

In the first step, the three models (USLE, RUSLE and MUSLE) are applied as they were developed by their founders. Then in a second step, an attempt was made to carefully adapt these formulas to the local characteristics of the watershed, but always within the limits of the necessary technical requirements of the modeling.

This adaptation takes into consideration certain aspects specific to this watershed: the density of faults and cracks on the one hand, and the predominance of soils of volcanic origin and those with a predominance of sand and newly formed clay elements on the other. The presence of stepped terraces testifies to the long work of erosion that has taken place on several occasions. Currently, in the context of climate change and the intensity of rainfall extremes, the nested terraces in the western part of the El Badalah basin will be threatened by the harmful effects of runoff if the farming society does not take preventive and pre-emptive measures.

\subsection{The USLE Equation}

This equation is based on the integration of 6 factors: slope value $(S)$, slope length $(L)$, rainfall erosivity $(R)$, soil erodibility $(R)$, land use $(C)$ and the role of managements $(P)$. 
It is expressed as follows:

$$
A_{\mathrm{USLE}}=R * K * L S * C * P .
$$

\subsection{The RUSLE Equation}

This is the revised USLE equation. It involves the same parameters, except the $L S$ factor which is calculated by multiplying the value of the slope by its length, but also by adding the parameter sedimentation flow calculated directly through the numerical model of the terrain under the function "hydrology".

This function allows to make a simulation of runoff that follows the line of the biggest slope. The advantage of this operation is that it estimates the quantity of rainwater that can be runoff in each pixel of the watershed, without considering the interception obstacles (vegetation cover and soil roughness) and evaporation. For the other parameters $(R, K, C$, and $P)$, they will be calculated as proposed by Wischmeir. It is expressed as follows:

$$
A_{\text {(RUSLE) }}=R \times K \times L S \times C \times P
$$

with $V$ : the total volume of runoff water; $Q p$ : the peak flow of the stream.

In the present research, the attempt to quantify soil losses is based on two steps. The first consists in applying these different equations in their original state without any intervention on the models. The second step consists in introducing an adjustment coefficient skilful of specifying as precisely as possible the share of infiltration water and that of water likely to run off under the influence of fractures that affect the watershed of Wadi El Badalah, whether these fractures are of tectonic origin (faults) or weathering origin (cracks).

\section{Parameters for Adapting the Models to Local Conditions in the Watershed}

The Asir region is known for its very ancient volcanic, granitic and metamorphic rocks that are largely affected by faults and fissures resulting from strong tectonic activity and long weathering processes (Adelinet, 2010; Solleiro-Rebolledo et al., 2019). These fractures affect runoff depending on the slope, density and direction of the fissures as well as the rate of the vegetation cover. The weighting of this adjustment coefficient was made on the basis of tests carried out on plots of $1 \mathrm{~m}^{2}$ outside the study area. This research was largely based on the results of geophysical surveys already exists (Elawadi et al., 2012). This technique allows to identify different sectors qualified to provide a good infiltration by magnetic, gravimetric and electrical prospection carried out for the Assir region (Figure 4).

The gravity infiltration index varies from (5.9) in the sector which represented a good performance in terms of gravity infiltration in the westearn part of the El Badalah basin and $(-4.9)$ in the sectors with a low gravity infiltration index in the central and northern parts of the basin (Elawadi et al., 2012) (Figure 4).

The latter parts are closely related to a heavy runoff that can cause a rapid flood in a short time in the south-eastern sector, then can disturbs the slopes and 


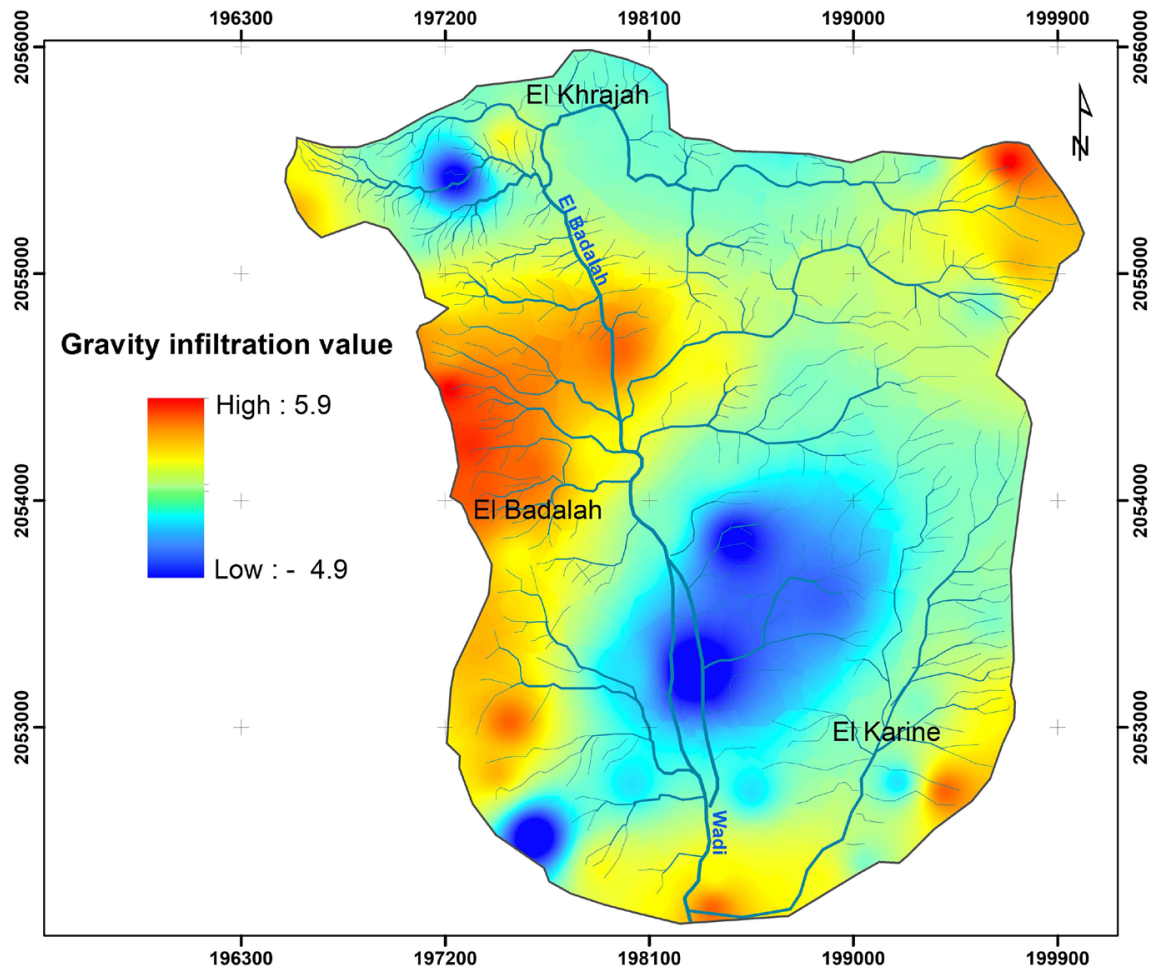

Figure 4. Gravity infiltration value estimated by magnetic, gravimetric and electrical method in El Badalah basin, (Source: Elawadi et al., 2012 result's applied with appropriate modification to the study area).

endangers the ancestral agricultural terraces. However, Account must be taken of the equation application based on this index, able to ameliorate the outcomes of the modelling process.

The first test was carried out on a soil overlying a massive and intact underlying rock. In this case, the runoff is much higher than the infiltration. The second test was carried out on a soil on a rock moderately fissured at the base. As a result, a noticeable reduction in runoff was observed compared to the first test. For the third plot, an intensely fissured underlying rock deeply altered was selected.

Runoff was further reduced, again in comparison with the first test. Therefore, the weighting of this coefficient was done on the basis of the density and direction of the fractures and the gradient of the slopes where they are located in order to be able to divide the El Badalah watershed into homogeneous units. For this reason, all the fractures were classified according to their density and the slope value to estimate their part in the improvement of the infiltration (Figure 5).

\section{Calculation and Mapping of the Different Parameters of the Models (USLE, RUSLE, MUSLE)}

\section{The $L S$ factor:}

It integrates the effect of the slope by its value and its length. Its calculation is obtained in different ways for the three models (USLE, RUSLE, MUSLE). It is expressed as follows: 


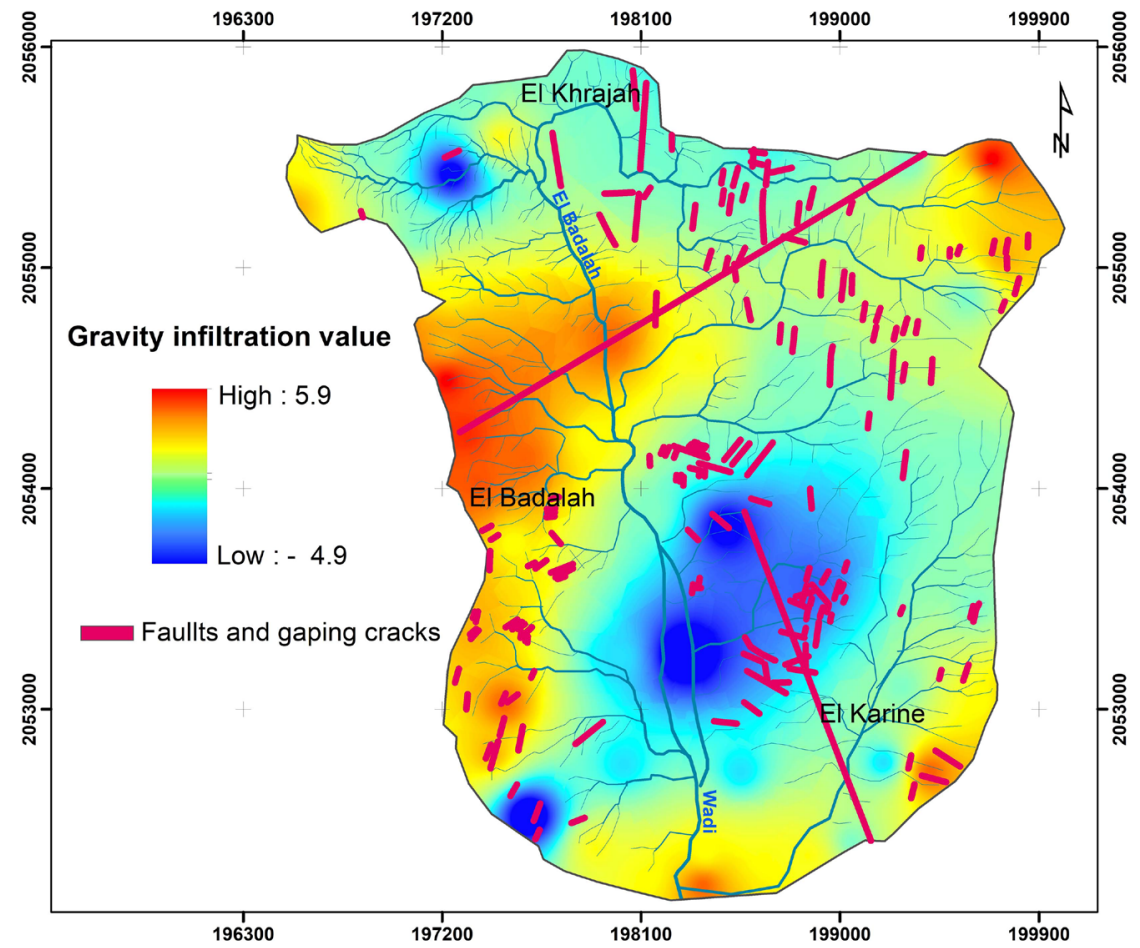

Figure 5. Fractures network taken into consideration in the modelling process with the gravity infiltration index in El Badalah basin defined as an adjustment index. (Source: Elawadi et al., 2012 result's, applied with appropriate modification to study area).

The $L S$ factor according to the USLE model Figure 6:

$$
\text { (USLE) } L S=\left(\frac{\lambda}{22.13}\right)^{m} \times 65.4 \sin 2 \beta+4.56 \sin \beta+0.0654
$$

with:

$\lambda$ slope length; $\beta$ slope value in degrees; $m=0.5$ if $\beta \geq 5 \%, m=0.3$ if $\beta<5 \%$, $\mathrm{m}=0.2$ if $\beta \leq 1$ (Wischmeier and Smith, 1975, 1978; Ezzaouini et al., 2020).

The $L S$ factor according to the RUSLE model:

$($ RUSLE $) L S=\left(\text { flow accumulation } \times \frac{\text { resolution }}{22.1}\right)^{m} \times\left(0.065+0.045 \times S+0.0065 \times S^{2}\right)(4)$ with $S$ value of the slope in \% (Djoukbala et al., 2018).

The $L S$ factor according to the MUSLE model:

$$
\left(\text { MUSLE) } L S=1.4 \times\left(\frac{A_{S}}{22.1}\right)^{0.4} \times\left(\frac{\sin (\theta \times 0.01745)}{0.09}\right)^{1.4}\right.
$$

with $\theta$ the value of the slope in degree and $A_{S}$ the corresponding surface calculated on the GIS.

After performing the appropriate calculations for each formula, the three maps of the distribution of the LS factor were obtained. Between the two models RUSLE and USLE the difference is very small, but in comparison with the MUSLE formula, the values of the $L S$ factor become more amplified (Figure 7). 


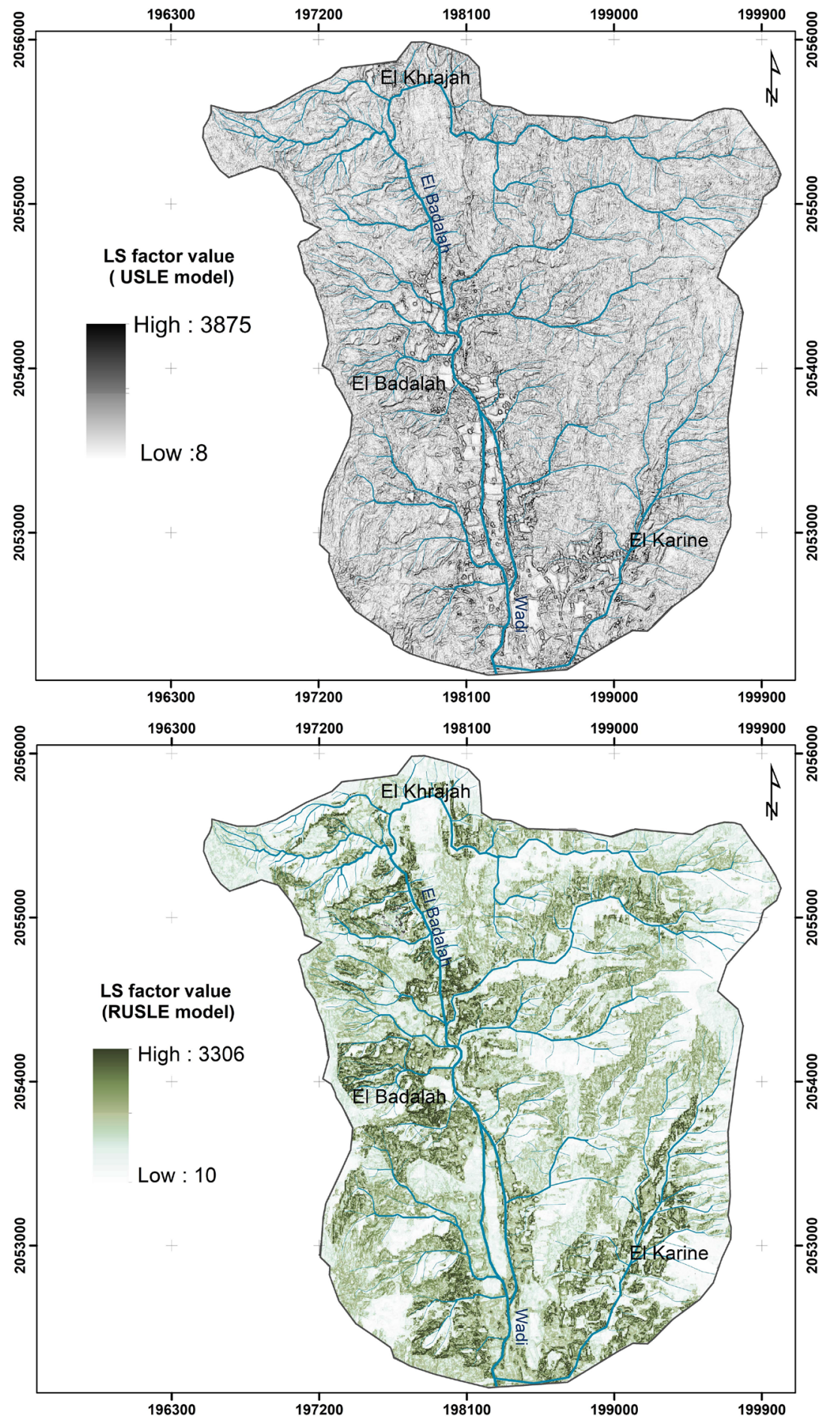

Figure 6. Map of $L S$ factor value according to USLE and RUSLE models.

\section{The $C$ Factor:}

This is a factor related to land use and vegetation cover. It estimates the suitability of each type of plant cover for soil protection. It is calculated on the same basis for all three models (Figure 8). The map is derived from a supervised classification of a Google Earth Pro image exported in UTM coordinates through the 


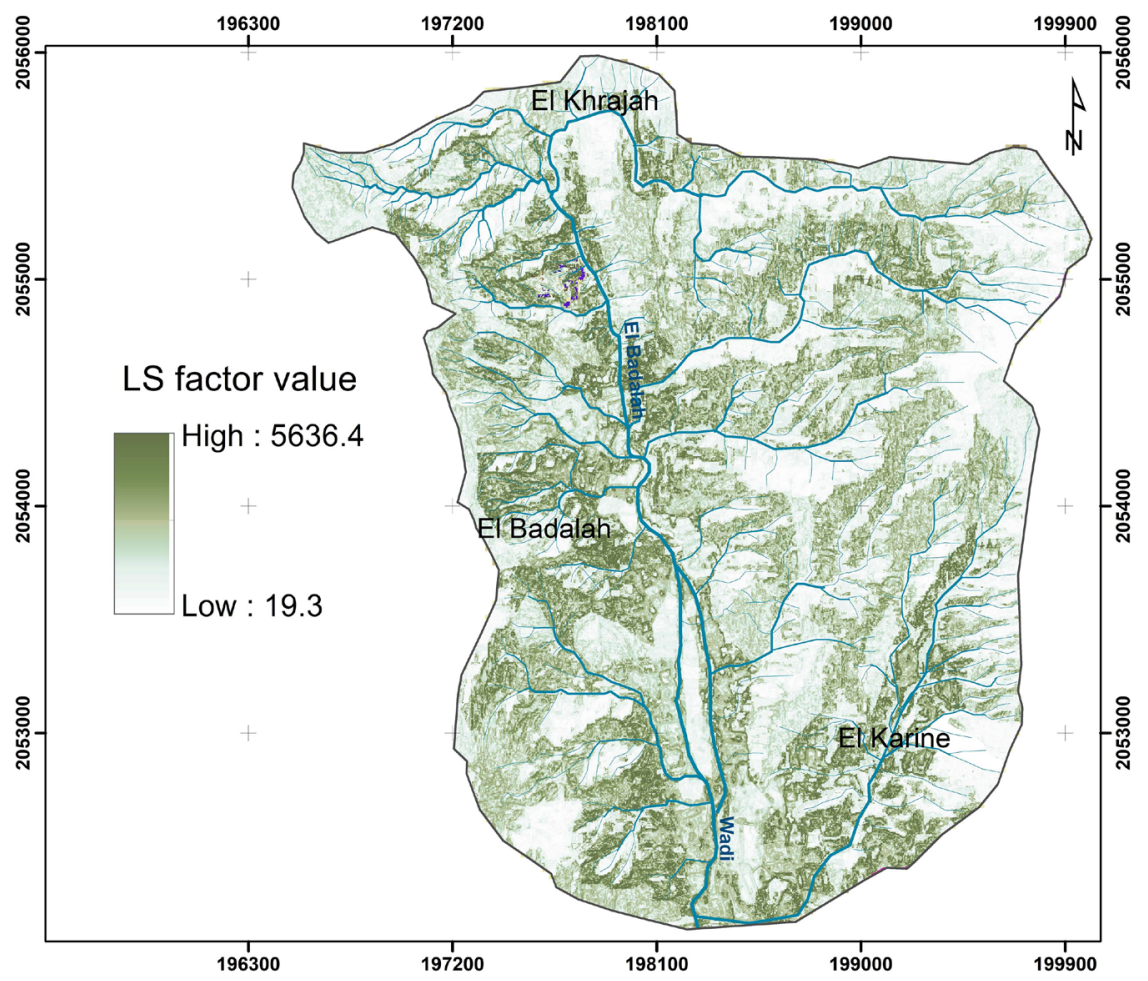

Figure 7. Map of $L S$ factor value according to MUSLE model.

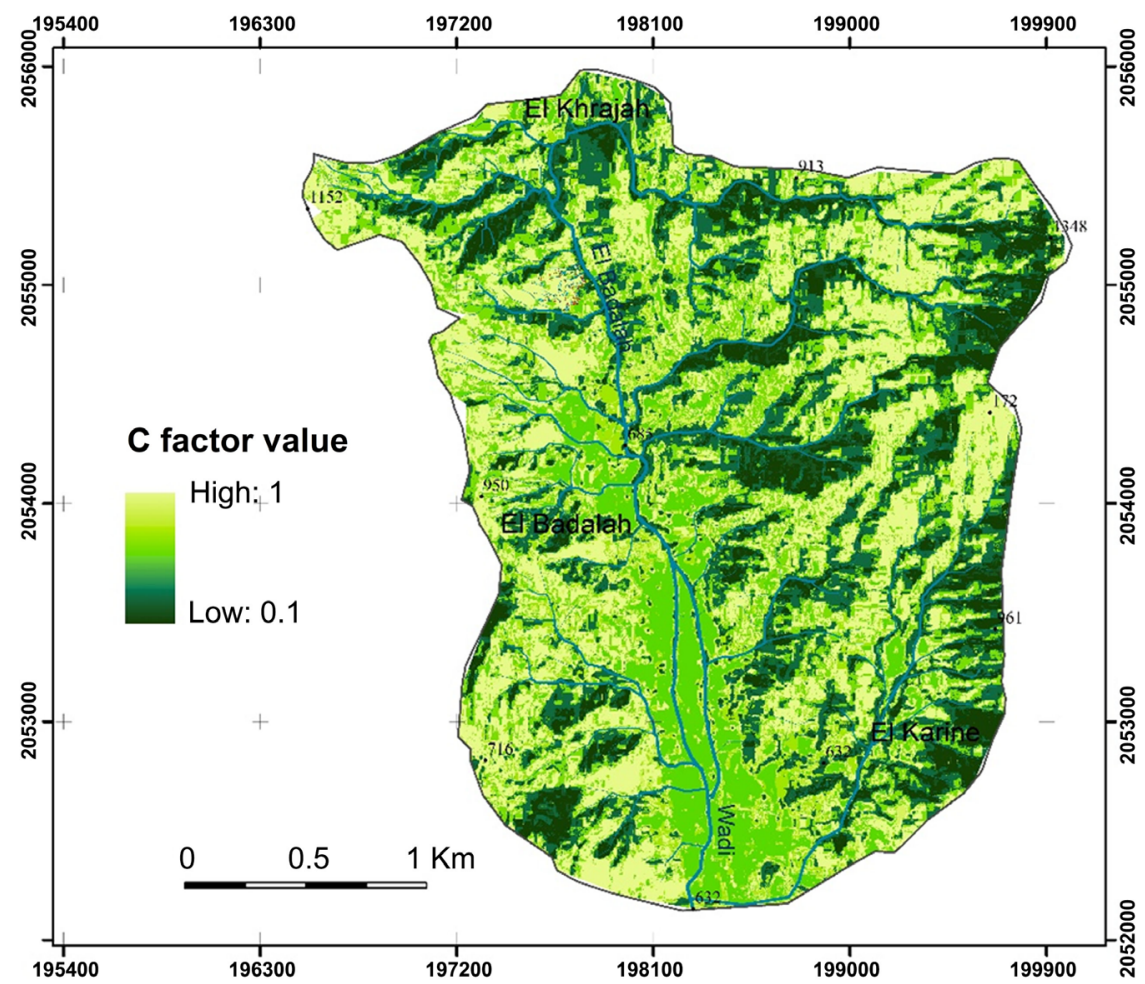

Figure 8. $C$ factor layer in El Badalah basin (Source: Google Earth pro 2020 Satellite).

map Puzzle software with high resolution. The natural vegetation cover occupies the high and middle slopes. Crops are concentrated on the agricultural terraces 
located on both sides of the main watercourse, on the middle and downstream course of the El Badalah wadi. Bare land and slopes with a very low density of vegetation cover show only a low protection for the soil with an index very close to 1 . It is the forests that provide the best protection for the soil with an erosion index of less than 0.2 (Figure 8).

\section{The $K$ factor:}

This is a factor that estimates the degree of resistance of each type of soil against erosive processes such as runoff. It is a coefficient that takes into consideration soil texture, structure, permeability and organic matter content. It is preferable to calculate this parameter starting from the results of granulometric and mineralogical analyses. It is also possible to use the textural triangle as a basis for calculating the $K$-factor directly on the Wischmeier nomograph.

In the case of the watershed of Wadi El Badalah, advantage was taken of the availability of the granulometric and mineralogical analyses carried out in the surrounding region of the study area and the soil texture map of the Asir region. Modeling results show that the most resistant soils are alluvial soils located on alluvial and agricultural terraces. While the most sensitive soils are located in the western upstream part of the El Badalah basin (Figure 9).

\section{The $R$ factor according to the USLE and RUSLE models:}

This is a factor that measures the effect of heavy rains on the soil in terms of both intensity and duration. It is obtained by applying Wischmeier's formula for both equations (USLE, RUSLE) (Toumi et al., 2013; Gwapedza, Hughes, \& Slaughter, 2018; Ezzaouini et al., 2020) (Figure 10).

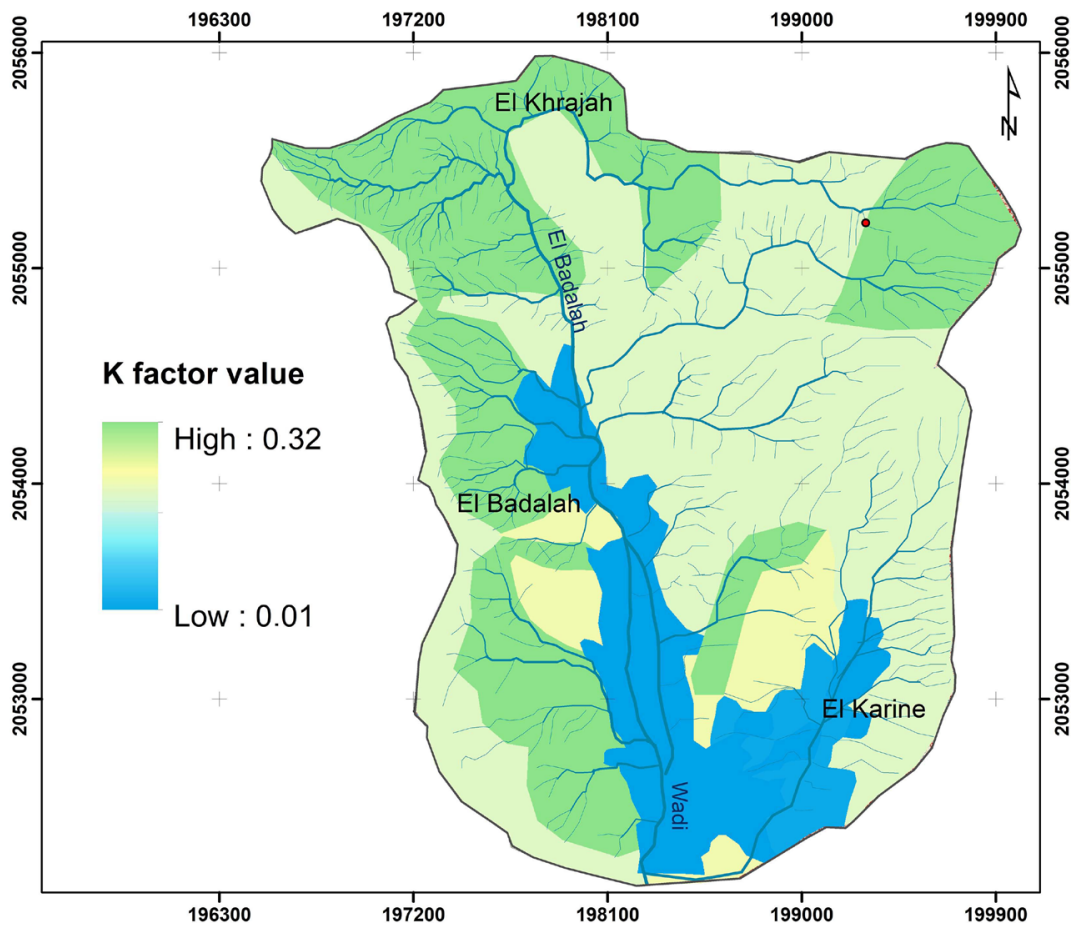

Figure 9. $K$-factor layer in El Badalah basin (Source: Ben Menaa el Amri, 2007 result's and geological map, applied with appropriate modification to study area). 


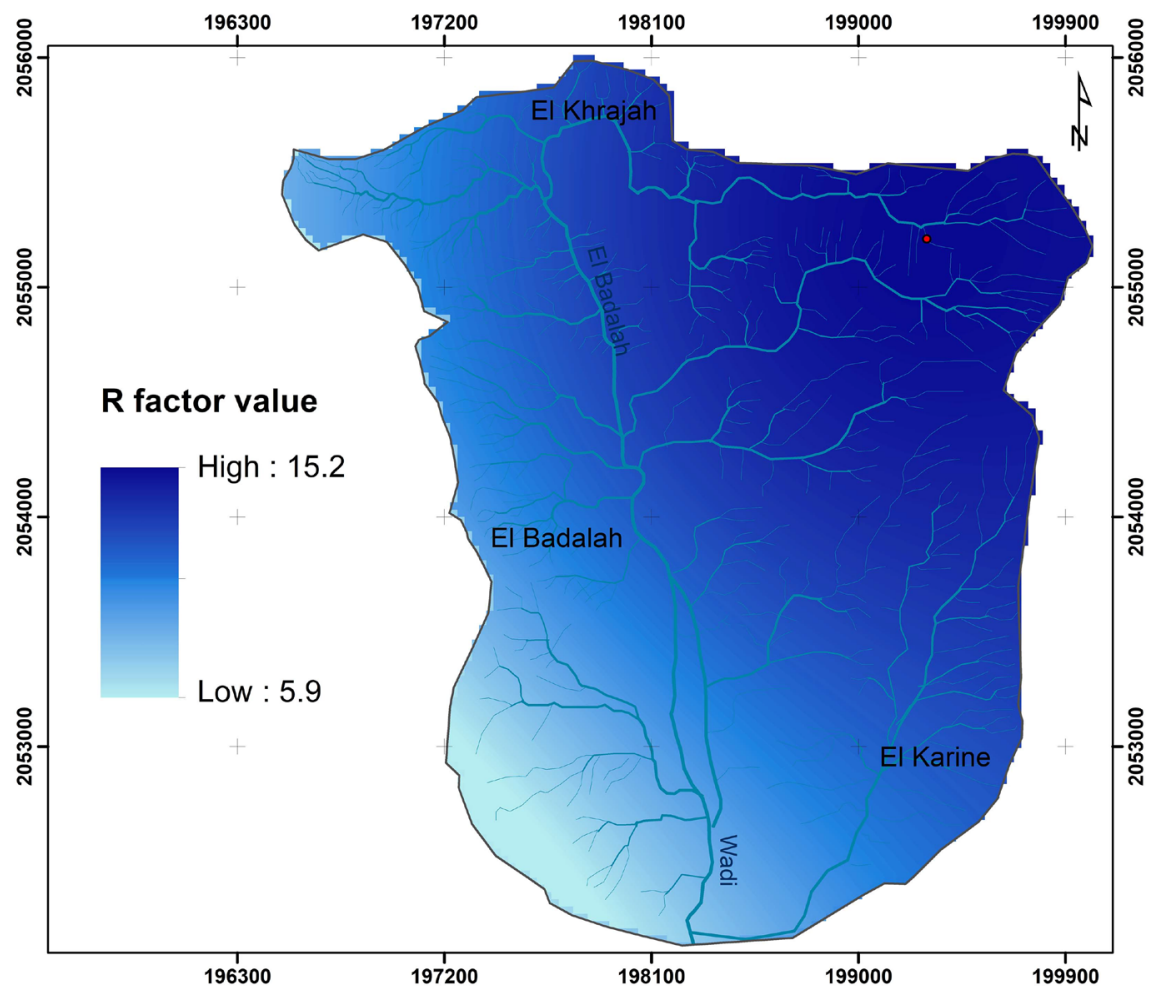

Figure 10. $R$ factor layer in El Badalah basin (Source: data processing).

It takes into account the kinetic energy, intensity and duration of the rainfall.

This index is of paramount importance in that it allows locating soils that have a low textural cohesion and are sensitive to the formation of soil crust, which makes the top layer of the soil impermeable and consequently allows runoff. Particularly in the lack of vegetation and summer fallow in agricultural land, often maintained before tillage (Tahiri et al., 2017; Ezzaouini et al., 2020). The spatial repartition of rainfall erosivity index in El Badalah basin was obtained by properly applying the Fournier modified equation through logarithmic language were applied for 4 stations located outside the study area. The modified equation is expressed in the following manner:

$$
\text { Fournier index }=p 2 / P
$$

\section{The $\mathrm{R}$ factor according to the MUSLE model:}

For the MUSLE equation, the factor is calculated according to the formula of Williams and Berndt developed in 1977. It was developed on the basis of total water flow volume and the peak flow of the main stream measured at the outlet basin (Williams, 1975; Williams \& Berndt, 1977; Demargne, 2001; Ezzaouini et al., 2020). In this case, an attempt was made to calculate the peak flow of the watershed based on the nearest rain control stations of Muhayl Asir, Abha, El Baha and Bisha using the three calculation models (Nouh, Farquharson and Al Subai, Ezzaouini et al., 2020, Figure 11).

The calculated index reflects the combined effect between heavy rains, the slope value and the soil texture (Nouh, 1987, 2006; Ezzaouini et al., 2020). 


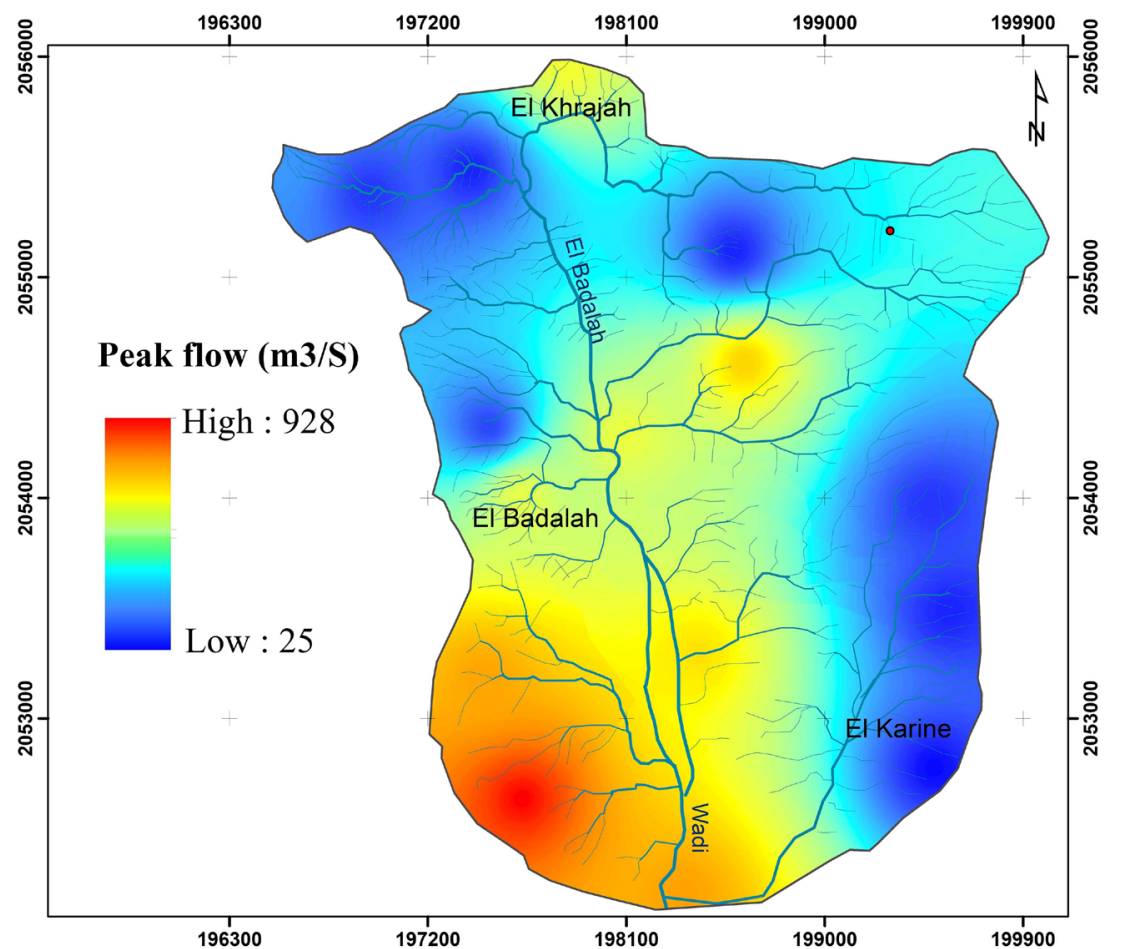

Figure 11. The peak flow depth distribution in El Badalah basin (Source: data processing 1978-2018).

$$
Q p=43 . \mathrm{A}^{0.522}(1992) \text {. }
$$

To make results more exactly, the map of runoff value helps to find the different sensitive sectors and identifies their evolution depending on the peak flow and runoff volume (Williams, 1975; Williams \& Berndt, 1977; Mohammad \& Adamowski, 2015; Ezzaouini et al., 2020) (Figure 12). All previous studies that have been carried on hydrology and erosion problem were found a close relationship between the erosion process, the ongoing sediment and the runoff value. A particular attention should be given to peak flow and runoff volume as an alternative input in the applied modelling process to calculate soil loss (MUSLE model), especially in mountain region affected by extreme rainstorm event at seasonal scale (Mohammad \& Adamowski, 2015; Ezzaouini et al., 2020). As has been mentioned earlier, it should be noted that rainstorm constitutes a significant amount of the annual rain in Asir region. This could provoke serious disturbance to the slope stability and decrease on the potential agriculture productivity of soil, especially for clayey soil with dominance of smectite clay that have a high swell-shrink character. The peak flow would probably have a bigger effect than regular rain on soil degradation. It has been observed on the map that the peak discharge rate in most parts of the basin is large but clear differences prevail between the central part and its two northwest and southeast extremities.

\section{The $P$ factor:}

This is an index that estimates the effect of agricultural practices and slope management on the rate of erosion. Only the central part of the watershed has 


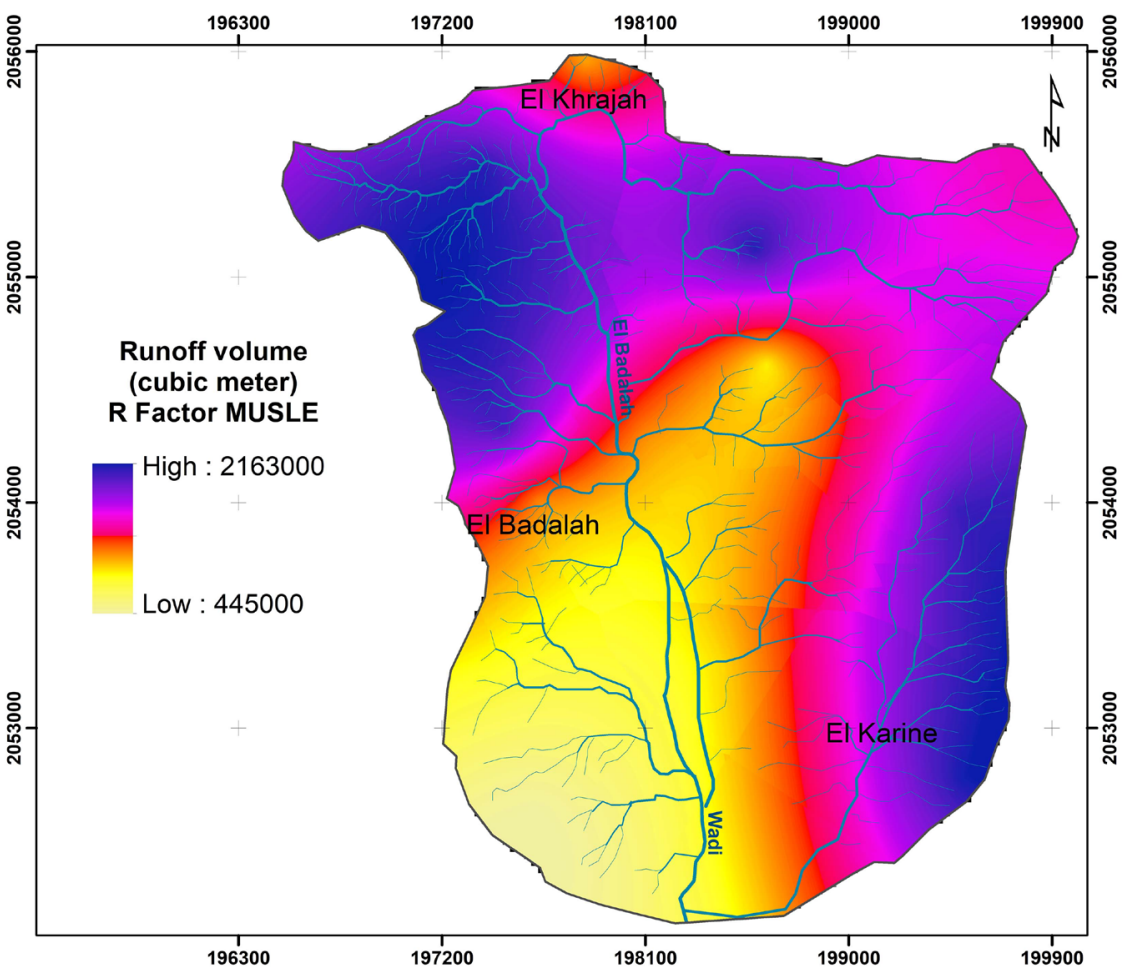

Figure 12. Runoff volume modelling of the El Badalah basin (Source: data processing 1978-2018).

benefited from the implementation of old anti-erosion measures. All this central part has known a rehabilitation and stabilization of the slopes using soft techniques (soil benches and dry stone bunds) with an erosivity index lower than 0.1, while in the remaining sectors that didn't have any type of management, the index reaches its maximum of 1 (Figure 13).

\section{Modeling Soil Losses: Results, Comparison and Discussion}

The results of the application of three equations (USLE, RUSLE and MUSLE), as well as the adjustment tests that have subsequently been developed, provide additional new insights into the process of erosion in the Asir region. The information obtained from the application of the three equations as proposed by the founders was insufficient to have a global idea of the different circumstances associated with soil degradation in the semi-arid region of Asir. However, the results of the modeling from three models, as well as the results of the adjusted modeling, showed that the pedological resources in this watershed are in a degradation phase despite the variations in the results. The contribution of three models in terms of quantifying soil losses shows that the USLE formula significantly underestimates soil losses compared to the results of the two other formulas (Felah, 2010; Azaiez, 2016, 2020b; Tahiri et al., 2017). This underestimation is attributable to model inputs that were specifically designed for plots on moderately steep slopes under local conditions specific to the United States.

The most degraded areas show a loss of $76 \mathrm{t} / \mathrm{ha} /$ year, mainly on the western 


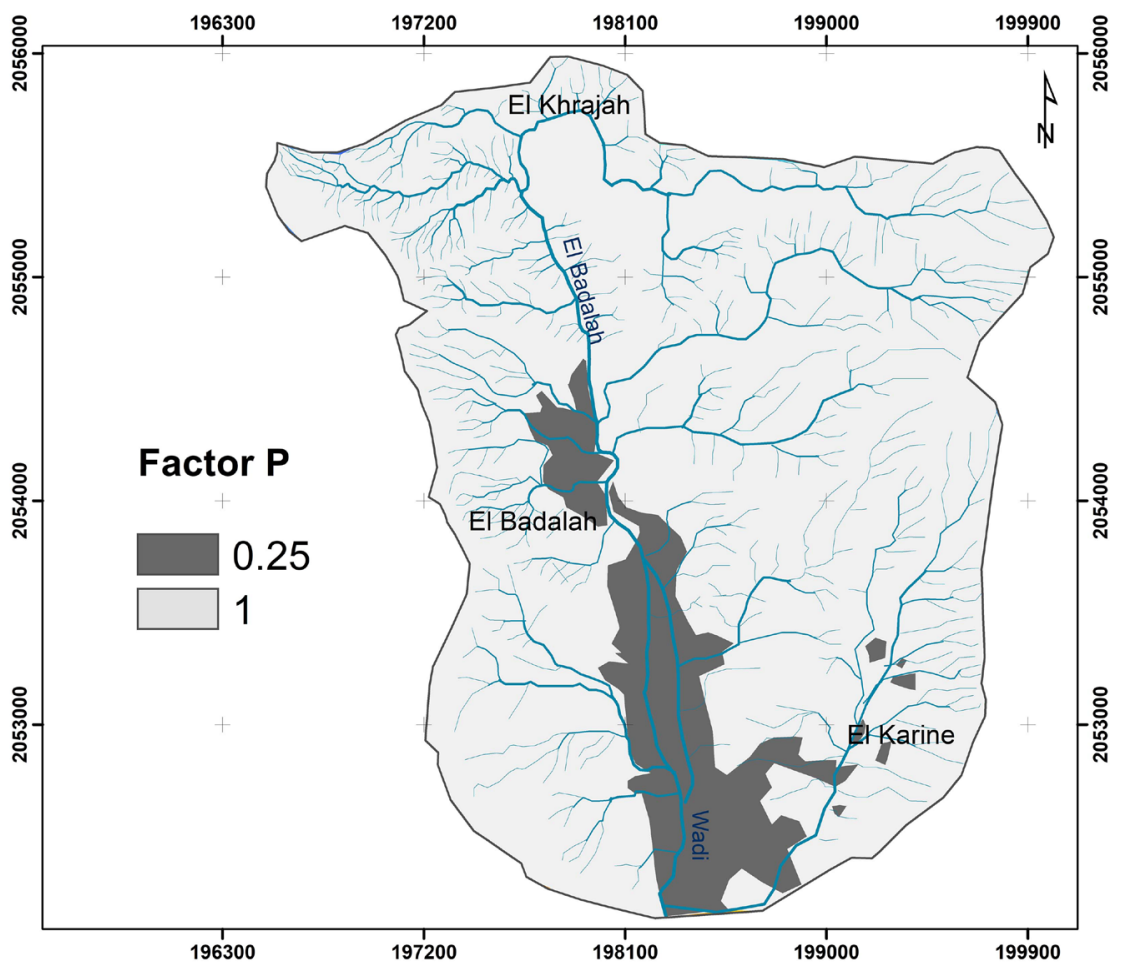

Figure 13. P factor layer in El Badalah basin (Source: Google Earth pro 2020 Satellite).

and extreme northeastern slopes, while the least affected slopes show a loss of less than $3 \mathrm{t} / \mathrm{ha} /$ year. However, it should be noted that soil losses due to linear erosion processes are not considered. Only sheet and gully erosion are quantified. The best advantage offered by this model is the possibility of comparing different agricultural systems. With the revised soil loss estimate (RUSLE), a significant improvement has been made in the accuracy of calculating the parameters, due to the automation of the modeling processes, which is increasingly based on software developed for specific purposes. The $L S$ factor is the most improved one in the RUSLE model. In addition to the length and value of the slope, it was possible to integrate its shape thanks to the "hydrology" function in Arc GIS. The maximum soil losses are around $115 \mathrm{t} / \mathrm{ha}$ /year, still in the western and extreme north-eastern sectors of the watershed. This distribution of losses reflects the combined effect of the slope and the aggressiveness of the rains (Figure 14). Estimating soil losses through the MUSLE equation goes one step further towards accuracy. The development of this formula came in response to the need to overcome the limitations of the first two models (Felah, 2010; Sadeghi et al., 2014; Azaiez, 2016; Azaiez, 2020a, 2020b). It was developed after extensive research, experimental trials in model fields and basins, and comparisons and validations to better understand the different mechanisms involved in water erosion in different climate contexts. The theoretical, methodological, and technical know-how in terms of knowledge of the erosion process was at the origin of the development of this equation. It is based on the notion of sediment production and takes into consideration runoff and the peak flow of the watercourse as fundamental 


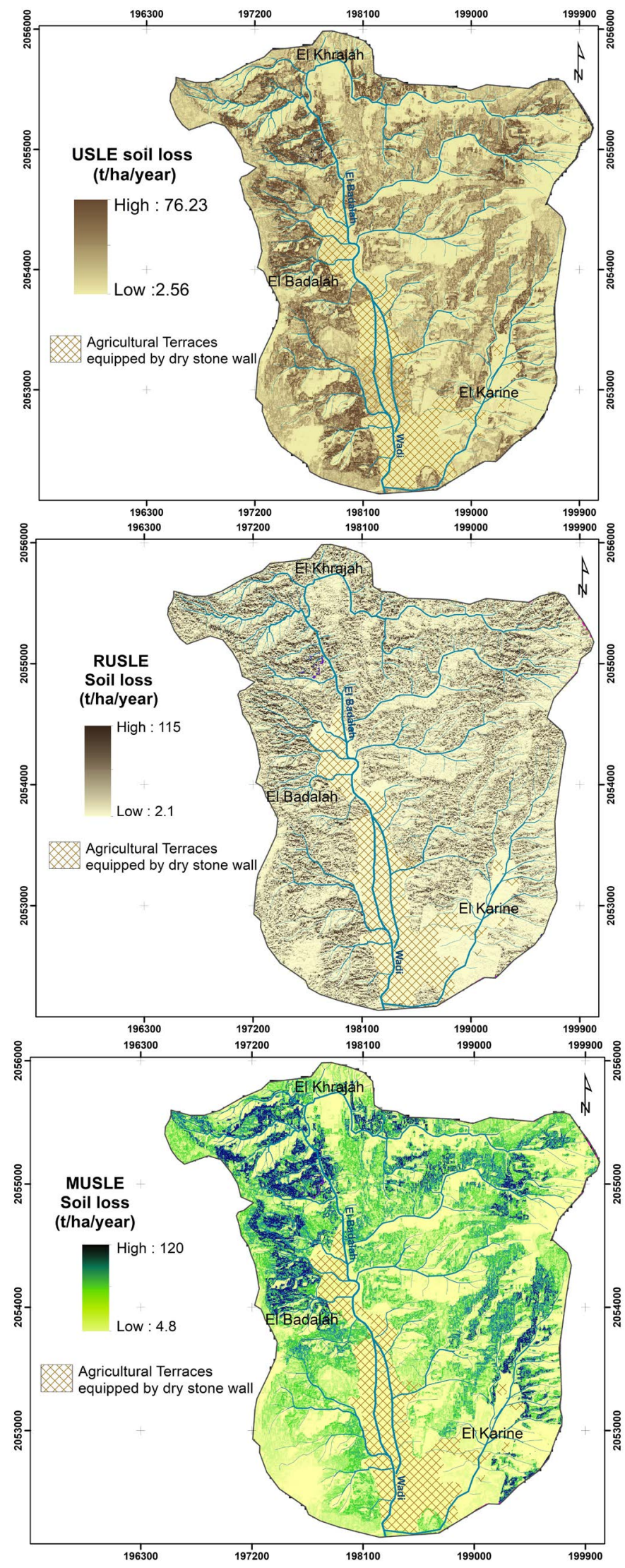

Figure 14. Modeling soil loss results by USLE, RUSLE and MUSLE models no adjusted. 
factors of water erosion. In order to calculate the runoff and peak flow, some morphometric and hypsometric parameters of the sub-watersheds must be taken into account, which could increase the efficiency of the MUSLE formula. Another advantage of this equation is that it gives a quantification of soil losses caused by sheet erosion and gullying, but only if turbidity and peak flow are measured at the main outlet of the watercourses. Indeed, the result of quantifying soil losses according to the MUSLE formula is significantly different from those of USLE and RUSLE in terms of intensity and spatial allocation. It is the northwestern, northeastern and eastern impluviums and interfluves that are most affected by land degradation. Maximum losses can exceed $120 \mathrm{t} / \mathrm{ha}$ /year, or $9 \%$ of the total surface area of the watershed. The central part is the least degraded and this is due to the effectiveness of the agricultural terraces and the quite dense riparian vegetation.

\section{The Soil Loss Resulting from the Adjustment of USLE, RUSLE and MUSLE Models}

The adjustment of these models is aimed to adapt them as well as possible to the local conditions of the Asir region while respecting the technical requirements of the modeling (Figures 15-17).

The weighted coefficient used is based on the density and direction of the fractures and the alignments of the subsoil resulting from the gravimetric and magnetic investigation modeling (Figures 15-17).

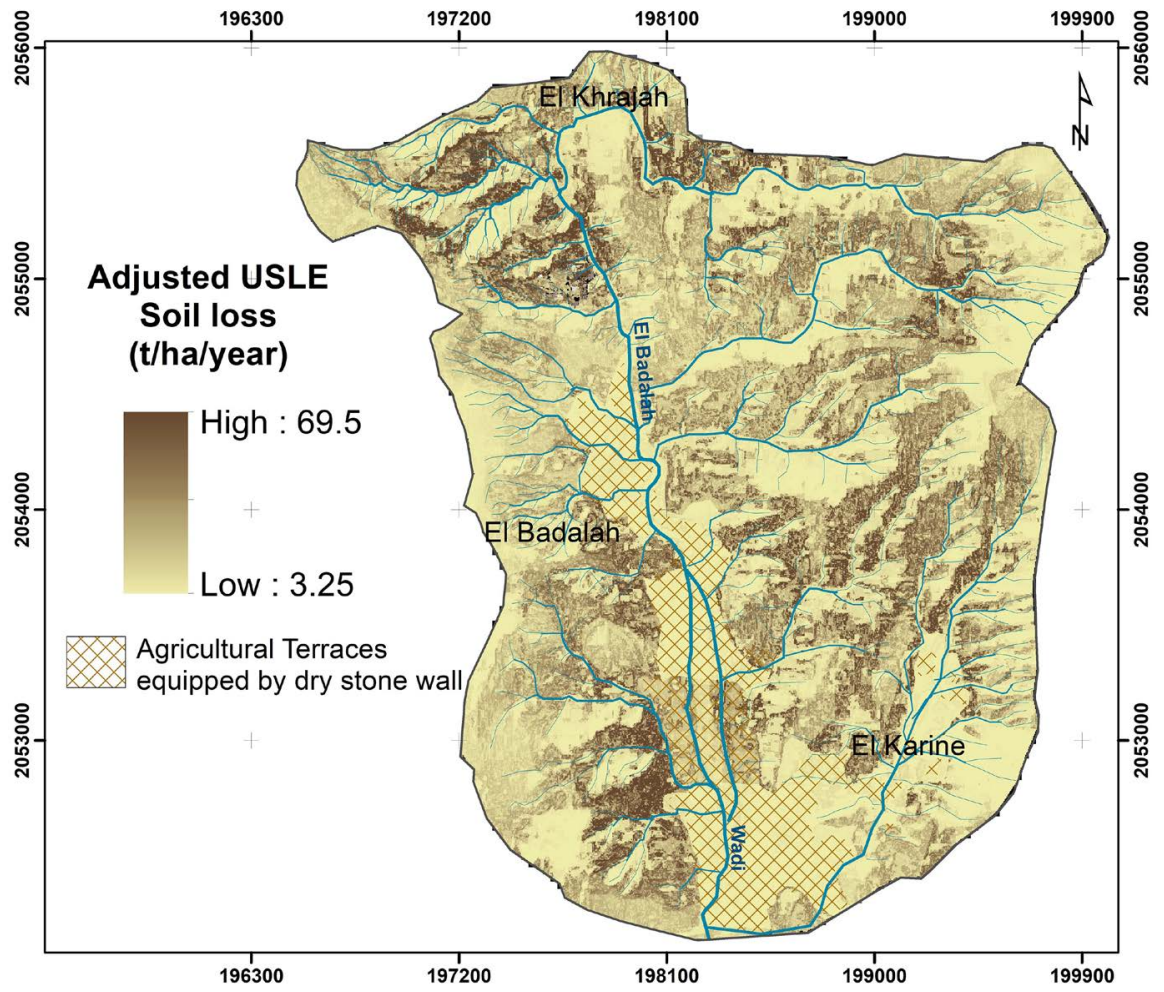

Figure 15. Modeling soil loss results by adjusted USLE model. 


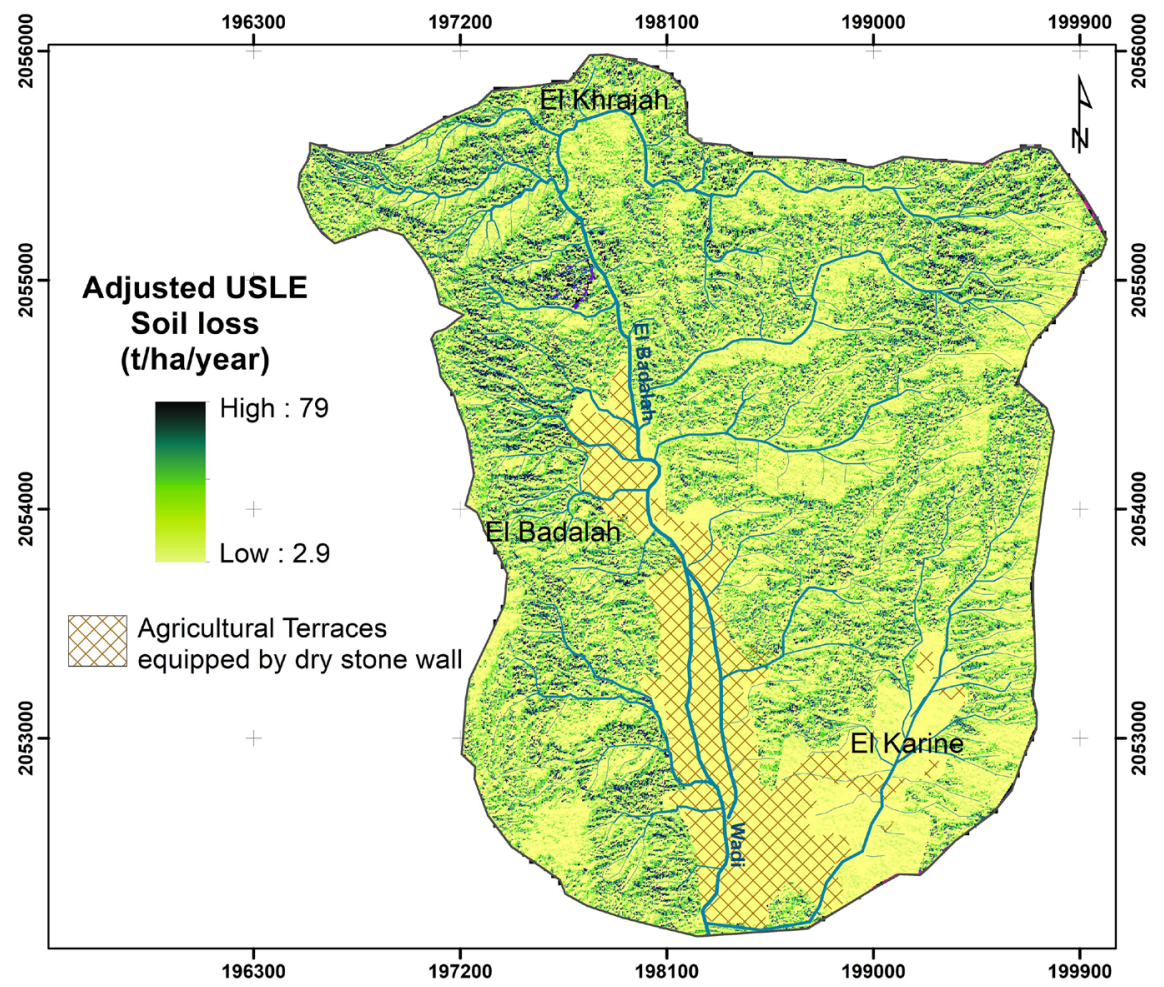

Figure 16. Modeling soil loss results by adjusted RUSLE model.

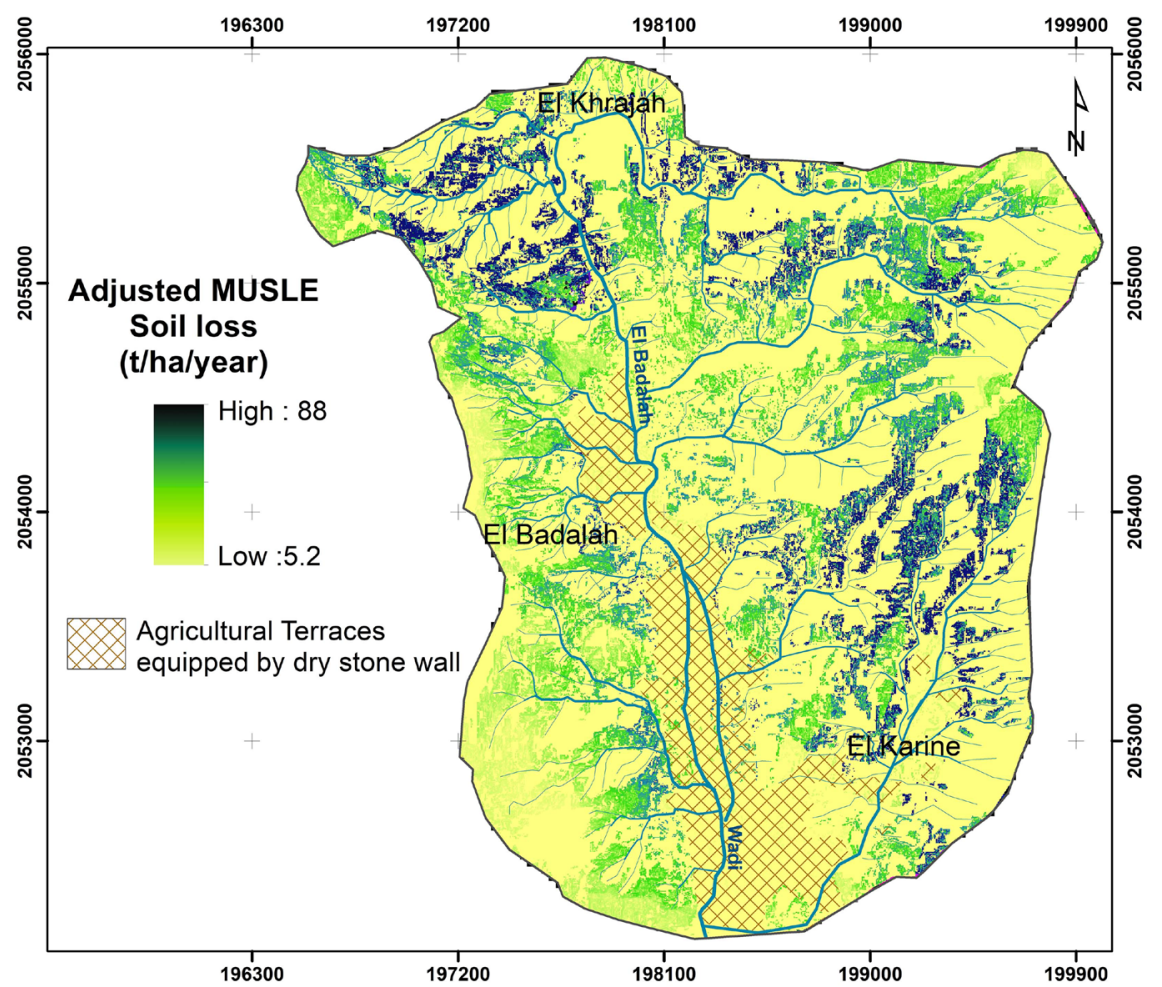

Figure 17. Modeling soil loss results by adjusted MUSLE model.

This parameter was used as a moderating factor of runoff and not as an amplifier. But a reproach can be made to this observation in case of the presence of 
horizontal fractures converging towards the center of the watershed. This situation can only amplify the concentration of runoff water on the middle and downstream course of the El Badalah wadi.

By adapting the MUSLE formula through the integration of additional data, soil losses change not only in terms of quantity but also in terms of distribution. The maximum losses are much less important ( $88 \mathrm{t} / \mathrm{ha} /$ year) and spatially they are less extensive, namely at only $6 \%$ of the total surface of the watershed. Another equally important fact is that one can get an idea of the erosive power of each downpour. This model makes it possible to calculate soil losses by working on precise rainfall events. This will be useful in specifying the different ways in which the problem of erosion can be managed according to the various factors associated with each rainfall event in different sector of El Badalah basin.

\section{Conclusion}

Thanks to the availability of data, the development of GIS for morpho-hydrological purposes and the accumulation of good know-how and ancestral skills in terms of erosion management, it was possible to apply a modeling of soil losses in the watershed of the wadi El Badalah. The results of the modeling from three models, as well as the results of the adjusted modeling, showed that the pedological resources in this watershed are in a degradation phase despite the variations in the results.

Through the application of the three models, the aim is not to completely stop erosion, but to encourage local stakeholders to reflect on solutions capable of keeping soil losses at least below tolerable limits by protecting ancestral skills and promoting improved management performance and developing policies and priorities to support soil and water resources. The erosion of agricultural land is an unavoidable real fact that is part of the natural hydrological cycle, even if it is very variable spatially and temporally. The present research may serve as a guide for local stakeholders to intervene in priority sectors that are subject to various erosive processes that sometimes manifest themselves in a very complex, combined way. The empirical models developed for the study of erosion are all of paramount importance, but they must be taken with caution, especially when they are not followed by experimental validation work in the field to evaluate their contribution and to determine the relevance of the soil conservation measures taken by the farmers and the State. The disappointing results in some sectors of El Badalah basin reveal to non-adoption of bench terraces in difficult slopes by the State to protect soil and enlarge the area suitable agriculture activity.

\section{Funding}

The author is funded through the Small Research Groups from the Deanship of Scientific Research at King Khalid University under research grant number (RGP. 1/235/1442). 


\section{Acknowledgements}

The author wishes to extend his appreciation and his gratitude to the Deanship of Scientific Research at King Khalid University Saudi Arabia for providing administrative and technical support and for funding this work through General Research Project (Small Research Groups) under grant number (RGP. 1/235/1442).

\section{Conflicts of Interest}

The author declares no conflicts of interest regarding the publication of this paper.

\section{References}

Adelinet, M. (2010). Du terrain au laboratoire, étude des propriétés élastiques du basalte (p. 202). Thèse de Doctorat, Le Mans: Université du Maine.

Azaiez, N. (2016). La dynamique géomorphologique actuelle dans le bassin versant de l'oued el Melah Bou el Ajraf: Cartographie et essai de quantification de l'érosion hydrique (271 p.). Thèse de Doctorat en géomorphologie.

Azaiez, N. (2020a). Soil Erosion Measurement Using Fallout Cesium 137 Technique in Sidi Salah Basin (Eastern Central Tunisia). GeoProgress Journal, 7, 11-35. http://www.geoprogress.eu/wp-content/uploads/2021/02/GeoJ2020-1.Naima_.pdf

Azaiez, N. (2020b). Modelling the Soil Loss in the Watershed of the Chaddad Wadi in Terms of Both Rockiness and Soil Slaking Indexes. International Journal of Geosciences, 11, 100-124. https://doi.org/10.4236/ijg.2020.113007

Azaiez, N., Alleoua, A., Baazaoui, N., \& Qhtani, N. (2020). Assessment of Soil Loss in the Mirabah Basin: An Overview of the Potential of Agricultural Terraces as Ancestral Practices (Saudi Arabia). Open Journal of Soil Science, 10, 159-180.

https://doi.org/10.4236/ojss.2020.105008

Ben Menaa el Amri, A. (2007). Pedological Characteristics of the Soil in Wadi Bisha (p. 171). Master Memory, Riyadh: King Saud University.

Bridgland, D., Westaway, R., \& Cordier, S. (2009). Les causes de l'étagement des terrasses alluviales à travers le monde. Quaternaire, 20, 5-23.

https://doi.org/10.4000/quaternaire.4994

Dautrebande, S., \& Sohier, C. (2006). L'érosion hydrique et les pertes en sols agricoles en région de Wallonne, FUSAGX (p. 122).

Demargne, C. (2001). La qualité des modèles numériques de terrain pour l'hydrologie. Application à la caractérisation des crues (275 p.). Thèse, Paris: Université de Marne-la-vallée.

Djoukbala, O., Hasbaia, M., Benselama, O., \& Mazour, M. (2018). Comparison of the Erosion Prediction Models from USLE, MUSLE and RUSLE in a Mediterranean Watershed, Case of Wadi Gazouana (N-W of Algeria), Modeling Earth Systems and Environment. https://doi.org/10.1007/s40808-018-0562-6

Elawadi, E., Saad Mogren, S., Ibrahim, E., Awni Batayneh, A., \& Al-Bassam, A. (2012). Utilizing Potential Field Data to Support Delineation of Groundwater Aquifers in the Southern Red Sea Coast, Saudi Arabia. Journal of Geophysics and Engineering, 9, 327-335. https://doi.org/10.1088/1742-2132/9/3/327

Ezzaouini, M. A., Mahé, G., Kacimi, I., \& Zerouali, A. (2020). Comparison of the MUSLE Model and Two Years of Solid Transport Measurement, in the Bouregreg Basin, and 
Impact on the Sedimentation in the Sidi Mohamed Ben Abdellah Reservoir, Morocco. Water, 12, 1882. https://doi.org/10.3390/w12071882

Felah, A. (2010). L'évaluation qualitative et quantitative de l'érosion des sols dans le Rif Central (Exemple: Bassin versant Aknoul). Publication: Association Tatouan Asmir, 183 p. (In Arabic)

Fontes, J. C., Pereirab, L. S., \& Smith, R. E. (2004). Runoff and Erosion in Volcanic Soils of Azores: Simulation with OPUS. https://doi.org/10.1016/j.catena.2003.10.011

Gwapedza, D., Hughes, D. A., \& Slaughter, A. R. (2018). Spatial Scale Dependency Issues in the Application of the Modified Universal Soil Loss Equation (MUSLE). Hydrological Sciences Journal, 63, 1890-1900. https://doi.org/10.1080/02626667.2018.1546388

Mohammad, F. S., \& Adamowski, J. (2015). Interfacing the Geographic Information System, Remote Sensing, and the Soil Conservation Service-Curve Number Method to Estimate Curve Number and Runoff Volume in the Asir Region of Saudi Arabia. Arabian Journal of Geosciences, 8, 11093-11105. https://doi.org/10.1007/s12517-015-1994-1

Nouh, M. (1987). A Comparison of Three Methods for Regional Flood Frequency Analysis in Saudi Arabia. Advances in Water Resources, 10, 212-219.

https://doi.org/10.1016/0309-1708(87)90031-5

Nouh, M. (2006). Wadi Flow in the Arabian Gulf States. Hydrological Processes, 20, 2393-2413. https://doi.org/10.1002/hyp.6051

Posthumus, H. (2005). Adoption of Terraces in the Peruvian Andes (p. 216). Tropical Resource Management Papers, No. 72, Wageningen: Wageningen University.

Roose, É., \& De Noni, G. (2004). Recherches sur l'érosion hydrique en Afrique: Revue et perspectives. Science et Changements Planétaires/Sécheresse, 15, 121-129.

Sadeghi, S. H. R., Gholami, L., Khaledi Darvishan, A., \& Saeidi, P. (2014). A Review of the Application of the MUSLE Model Worldwide. Hydrological Sciences Journal, 59, 365-375. https://doi.org/10.1080/02626667.2013.866239

Shi, Q. W. (2014). Flood Hazard Assessment along the Western Regions of Saudi Arabia Using GIS-Based Morphometry and Remote Sensing Techniques (p. 103). Thesis for the Degree of Master of Science, Thuwal: King Abdullah University of Science and Technology.

Solleiro-Rebolledo, E., Rivera-Uria, Y., Chávez-Vergara, B., Díaz-Ortega, J., Sedov, S., Alcalá-Martínez, J. R., Beltrán-Paz, O. I., \& Martínez-Jardines, L. G. (2019). Evolution of the Landscape and Pedodiversity on Volcanic Deposits in the South of the Basin of Mexico and Its Relationship with Agricultural Activities. Terra Latino Americana, 37, 501-518. https://doi.org/10.28940/terra.v37i4.565

Tahiri, M., Tabyaoui, H., El Hammichi, F., Achab, M., Tahiri, A., \& El Hadi, H. (2017). Quantification of Water Erosion and Sedimentation Using Empirical Models in the Tahaddart Watershed (Northwestern Rif, Morocco). Bulletin de l'Institut Scientifique, Rabat, Section Sciences de la Terre, 39, 87-101.

Toumi, S., Meddi, M., Mahe, G., \& Brou, Y. T. (2013). Cartographie de l'érosion dans le bassin versant de l'Oued Mina en Algérie par télédétection et SIG. Hydrological Sciences Journal, 58, 1-17. https://doi.org/10.1080/02626667.2013.824088

Williams, J. R. (1975). Sediment-Yield Prediction with Universal Equation Using Runoff Energy Factor (Volume 40, p. 244). Washington DC: ARS-S, Southern Region, Agricultural Research Service, US Department of Agriculture.

Williams, J. R., \& Berndt, H. D. (1977). Sediment Yield Prediction Based on Watershed Hydrology. Transactions of the ASAE, 20, 1100-1104.

https://doi.org/10.13031/2013.35710 
Wischmeier, W. H., \& Smith, D. D. (1975). Predicting Rainfall-Erosion Losses from Cropland East of the Rocky Mountains: Guide for Selection of Practices for Soil and Water Conservation. Washington DC: US Department of Agriculture.

Wischmeier, W. H., \& Smith, D. D. (1978). Predicting Rainfall Erosion Losses: A Guide to Conservation Planning. Washington DC: Department of Agriculture, Science and Education Administration. 